\title{
Possible role of exogenous melatonin in preventing more serious COVID-19 infection in patients with type 2 diabetes mellitus
}

\author{
Wagner José Martorina1* (D), Almir Tavares ${ }^{1}$
}

\section{SUMMARY}

COVID-19 infection is more severe in patients with type 2 diabetes mellitus (DM2). The severity of this viral infection is associated with an intense inflammatory activity. DM2 is a disease that also determines a greater degree of systemic inflammation. This is due to hyperglycemia, the higher prevalence of sleep disorders and also the low levels of melatonin, a substance with anti-inflammatory actions, in these patients. In this article, we suggest that exogenous melatonin may have an important anti-inflammatory role in preventing severe forms of COVID -19 in patients with DM2.

KEYWORDS: Diabetes mellitus. Melatonin. Sleep. Coronavirus Infections. COVID-19.

\section{INTRODUCTION}

The COVID-19 pandemic manifests itself with particularly adverse outcomes for some groups. Patients with heart disease, lung disease, senility, obesity, and DM2 frequently evolve to severer forms of COVID-19, with respiratory failure and death ${ }^{1}$. Understanding such vulnerability can be an important step to improve the knowledge about the Covid pathophysiology. COVID-19 presents an initial infectious phase, which later evolves into a second phase inflammatory, with greater repercussion and severity. The risk groups present pathologies that bear a common link. They exhibit a previous significant increase in inflammatory activity, which combined with the inflammation generated by COVID-19, could result in a worsening evolution ${ }^{2}$.

In diabetes mellitus, systemic inflammation is well known as it results in chronic complications of the disease. Part of this inflammation is due to hyperglycemia ${ }^{3}$. Another significant part of this inflammation is secondary to sleep disorders (sleep deprivation, insomnia, sleep-related breathing disorders, and circadian rhythm sleep-wake disorders) very prevalent in these patients ${ }^{4}$. In addition to a greater circulation of inflammatory agents, both DM2 and sleep disorders determine a lower amount of an important anti-inflammatory agent: melatonin ${ }^{5-7}$. The patient with DM2, therefore, has two reasons for presenting with higher inflammatory status: more inflammatory agents and less anti-inflammatory agents. This can justify the development more likely of severe acute inflammatory reactions in the second phase of COVID-19. In this context, melatonin with its anti-inflammatory properties can be a promising drug. In addition to its direct anti-inflammatory activity ${ }^{7,8}$, melatonin can treat sleep disorders common in these patients ${ }^{9-12}$ which would further contribute to reducing baseline inflammation. In this article, we will discuss the pathophysiological basis and perspectives for the prophylactic use of melatonin to prevent severe forms of COVID-19 in patients with DM2. We hypothesized that the use of melatonin even before infection can protect patients with diabetes from severe forms of the disease.

\footnotetext{
'Universidade Federal de Minas Gerais, Postgraduate Program in Neurosciences - Belo Horizonte, Brazil.

*Corresponding author: wmartorina@yahoo.com

Conflicts of interest: the authors declare there are no conflicts of interest. Funding: none.

Received on November 10, 2020. Accepted on December 13, 2020.
} 


\section{COVID-19 AND INFLAMMATION: PATHOPHYSIOLOGY}

The most severe manifestations of COVID-19, such as acute respiratory syndrome, appear to be associated with an exacerbated inflammatory response, which occurs after an initial phase of mild symptoms, such as cough and fever ${ }^{13,14}$. This response has been called a cytokine storm. In vitro, it was shown that initially there is a delay in the production of cytokines, such as interferons, and recruitment of CD8 T cells, responsible for immune response to infections. These mechanisms allow greater initial viral replication and could explain the paucity of symptoms at the initial phase, with low inflammatory activity. Subsequently, there is a rapid increase in cytokines and inflammatory cells in tissues, leading suddenly to acute and intense clinical manifestations. Interferon alpha/beta, interleukins 1 , 6,8 , reactive oxygen species (ROS), oxidative enzymes, and tumor necrosis factors, produced by macrophages, take part in this immune response ${ }^{15}$. The acute inflammatory storm is responsible for the multiple organ failure seen in COVID19. Inflammatory markers, such as ferritin and D-dimer, and a drop in the number of platelets appear as capable of predicting this intense inflammatory activity ${ }^{16}$. Currently, no medications were competent to prevent serious forms of COVID-19 infection. A recent study, for example, showed that hydroxychloroquine - one of the most discussed medications in scientific and political circles $3 / 4$ did not show benefits for the prevention of COVID-19 ${ }^{17}$. Finding a drug that reduces the chance of severe infection seems particularly vital in groups at risk, such as those composed of patients with greater previous baseline inflammatory activity: DM2, sleep disorders, or both conditions.

\section{DIABETES MELLITUS, SLEEP AND INFLAMMATION}

DM2 is a disease characterized by chronic hyperglycemia. This hyperglycemia leads to an inflammatory and also an immune imbalance. The inflammation occurs by activation of the polyol pathway, increased formation of end products of advanced glycosylation and protein $\mathrm{C}$ kinase isoforms, and increased influx of ROS into cells. ROS induces epigenetic changes by altering pro-inflammatory genes, thus perpetuating the inflammatory process even after hyperglycemia is resolved. Immunological imbalance can be observed by helper $T$ cells 1 and 2 which produce an excess of anti and pro-inflammatory factors ${ }^{18}$. Similar imbalances are present in severe forms of COVID-19, where there is excessive inflammatory activity and anomalous immunomodulation sometimes inhibits and other times over-activates inflammatory mechanisms ${ }^{19}$.
In DM2, in addition to hyperglycemia, frequent sleep disorders contribute to a chronic elevation of the basal inflammatory status. Previous studies found that sleeping fewer hours per night can lead to activation of interleukins and tumor necrosis factors. Not only shorter sleep duration, but poor sleep quality can increase inflammatory status. Finally, sleep apnea, through intermittent nocturnal hypoxemia, can lead to the exacerbation of chronic systemic inflammation ${ }^{5-7}$. Therefore, as sleep disorders are frequent in DM2 is reasonable to think that this fact may contribute to severe forms of COVID-19 that are related to a higher inflammatory status.

\section{MELATONIN AND COVID 19 PREVENTION: WHAT WOULD BE THE RATIONALE?}

Some data suggest a possible protective and preventive role of melatonin in DM2 against COVID-19 $9^{19-22}$. Microbats of the genus Rhinolophus are natural carriers of coronaviruses. These animals act as hosts and can transmit coronaviruses that are highly pathogenic to humans and livestock. Despite carrying coronavirus for long periods, these bats normally do not suffer from clinical symptoms and consequences of the infection $^{23}$. Because they rest in ill-illuminated caves during the day and are active in the darkness of the night, they are constantly protected against sunlight. The available data indicate that their melatonin is kept at much higher levels in comparison to those in humans, throughout day and night ${ }^{23}$. The improved immunological ability against coronavirus pathology observed in these bats might bear relationships to this continuously higher level of melatonin in these nocturnal mammals.

The most serious forms of COVID-19 occurred in older people and melatonin levels tend to reduce importantly as age advances ${ }^{21}$. Previous studies have shown that low levels of melatonin are associated with an increased risk of DM2 $2^{24,25}$. This data is reinforced by studies that showed a higher risk of DM2 related to the presence of melatonin receptor 2 (MTR2), a polymorphism present in the pancreatic beta cell ${ }^{26}$. Would be lower levels of melatonin associated with a higher prevalence of severe symptoms in DM2?

One of the consequences of COVID-19 infection is the inability of macrophage mitochondria to produce melatonin. These cells adopt aerobic glycolysis, becoming highly inflammatory and hindering the production of coenzyme A from pyruvate. Melatonin absence at mitochondrial level prevents neutralization of free radicals and inflammatory cytokines capable of tissue damage ${ }^{19}$. In addition, melatonin has vasodilator activity-dependent and independent of nitric oxide. This latter effect would be associated with activation of the prostaglandin 
pathway. This mechanism would also be associated with the antioxidant and anti-inflammatory activities of melatonin and would prevent lesions in pulmonary vasculature at endothelial level, thus avoiding progression to pulmonary hypertension and cardiac injury ${ }^{27}$. Some authors suggest that melatonin could be used in sleep-deprived, inflamed patients to prevent lung injuries in the case of infection by COVID- $19^{15}$. In advanced stages of infection by COVID-19, it is also postulated that melatonin has an effect to suppress the NOD-like receptor 3, a receptor capable of amplifying inflammation ${ }^{20}$. Thus, there would be suppression of cytokine storm in the second phase of the disease. In elderly DM2 sleep-deprived patients, melatonin levels are lower, NOD-like receptor 3 (NLRP3) is not inhibited, and greater COVID-19 severity is expected. Melatonin has a mild profile of side-effects and drug interactions and is not unrecommended in the 2019 edition of the American Geriatrics Society Updated Beers Criteria for Potentially Inappropriate Medication Use in Older Adults ${ }^{28}$. Future clinical trials could determine its therapeutic role here.

\section{CONCLUSION}

We conclude that melatonin modulates protective mechanisms against COVID-19. Melatonin can be safely administered to DM2 sleep-deprived elderly patients. It is not listed in the 2019 edition of the American Geriatrics Society updated Beers Criteria for potentially inappropriate medication use in older adults. It has good tolerability and the incidence of side effects is low. Melatonin can be part of preventive interventions to avoid the progression from mild to severe forms of COVID-19 in association with other health measures. Randomized clinical trials are needed to assess whether such actions of exogenous melatonin would be similar to the paracrine actions of these substances.

\section{AUTHOR'S CONTRIBUTION}

AT: Conceptualization, Methodology, Writing - Original Draft, Writing - Review \& Editing. WJM: Conceptualization, Methodology, Writing - Original Draft, Writing - Review \& Editing.

\section{REFERENCES}

1. Siordia JA Jr. Epidemiology and clinical features of COVID-19: a review of current literature. J Clin Virol. 2020;127:104357. https://doi.org/10.1016/j.jcv.2020.104357

2. Stein RA. COVID-19: risk groups, mechanistic insights and challenges. Int J Clin Pract. 2020;74(8):e13512. https://doi. org/10.1111/ijcp.13512

3. Bigagli E, Lodovici M. Circulating oxidative stress biomarkers in clinical studies on type 2 diabetes and its complications. Oxid Med Cell Longev. 2019;2019:5953685. https://doi. org/10.1155/2019/5953685

4. Martorina W, Tavares A. Real-world data in support of short sleep duration with poor glycemic control, in people with type 2 diabetes mellitus. J Diabetes Res. 2019;2019:6297162. https://doi.org/10.1155/2019/6297162

5. Pinto AR, Silva NC, Pinato L. Analyses of melatonin, cytokines, and sleep in chronic renal failure. Sleep Breath. 2016;20(1):339-44. https://doi.org/10.1007/s11325-0151240-9

6. Ming H, Tian A, Liu B, Hu Y, Liu C, Chen R, et al. Inflammatory cytokines tumor necrosis factor- $\alpha$, interleukin- 8 and sleep monitoring in patients with obstructive sleep apnea syndrome. Exp Ther Med. 2019;17(3):1766-70. https://doi.org/10.3892/ etm.2018.7110

7. Celinski K, Konturek PC, Slomka M, Cichoz-Lach H, Brzozowski T, Konturek SJ, et al. Effects of treatment with melatonin and tryptophan on liver enzymes, parameters of fat metabolism and plasma levels of cytokines in patients with non-alcoholic fatty liver disease--14 months follow up. J Physiol Pharmacol. 2014;65(1):75-82. PMID: 24622832
8. Sakr HF, Al-Ani B. Modulation of proinflammatory cytokines and leukocyte mobilization by melatonin in response to sterile tissue injury in Wistar albino rats. Saudi Med J. 2013;34(5):470-6. PMID: 23677262

9. Bano-Otalora B, Madrid JA, Rol MA. Melatonin alleviates circadian system disruption induced by chronic shifts of the lightdark cycle in Octodon degus. J Pineal Res. 2020;68(1):e12619. https://doi.org/10.1111/jpi.12619

10. Zambrelli E, Canevini M, Gambini O, D’Agostino A. Delirium and sleep disturbances in COVID-19: a possible role for melatonin in hospitalized patients? Sleep Med. 2020;70:111. https://doi.org/10.1016/j.sleep.2020.04.006

11. Mozdzan M, Mozdzan M, Chalubinski M, Wojdan K, Broncel $M$. The effect of melatonin on circadian blood pressure in patients with type 2 diabetes and essential hypertension. Arch Med Sci. 2014;10(4):669-75. https://doi.org/10.5114/ aoms.2014.44858

12. Schaefer C, Kunz D, Bes F. Melatonin effects in REM sleep behavior disorder associated with obstructive sleep apnea syndrome: a case series. Curr Alzheimer Res. 2017;14(10):1084-9. https:// doi.org/10.2174/1567205014666170523094938

13. Sanders JM, Monogue ML, Jodlowski TZ, Cutrell JB. Pharmacologic treatments for coronavirus disease 2019 (COVID-19): a review. JAMA. 2020;323(18):1824-1836. https://doi.org/10.1001/jama.2020.6019

14. Park M, Cook AR, Lim JT, Sun Y, Dickens BL. A systematic review of COVID-19 epidemiology based on current evidence. J Clin Med. 2020;9(4):967. https://doi.org/10.3390/ jcm9040967 
15. Salles C. Correspondence COVID-19: melatonin as a potential adjuvant treatment. Life Sci. 2020;253:117716. https://doi. org/10.1016/j.lfs.2020.117716

16. Mehta P, McAuley DF, Brown M, Sanchez E, Tattersall RS, Manson JJ, et al. COVID-19: consider cytokine storm syndromes and immunosuppression. Lancet. 2020;395(10229):1033-4. https://doi.org/10.1016/S0140-6736(20)30628-0

17. Boulware DR, Pullen MF, Bangdiwala AS, Pastick KA, Lofgren $\mathrm{SM}$, Okafor EC, et al. A randomized trial of hydroxychloroquine as postexposure prophylaxis for Covid-19. N Engl J Med. 2020;383(6):517-25. https://doi.org/10.1056/NEJMoa2016638

18. Mahlangu T, Dludla PV, Nyambuya TM, Mxinwa V, MazibukoMbeje SE, Cirilli I, et al. A systematic review on the functional role of Th1/Th2 cytokines in type 2 diabetes and related metabolic complications. Cytokine. 2020;126:154892. https:// doi.org/10.1016/j.cyto.2019.154892

19. Reiter RJ, Sharma R, Ma Q, Dominquez-Rodriguez A, Marik PE, Abreu-Gonzalez P. Melatonin inhibits COVID-19-induced cytokine storm by reversing aerobic glycolysis in immune cells: a mechanistic analysis. Med Drug Discov. 2020:100044. https://doi.org/10.1016/j.medidd.2020.100044

20. Zhang R, Wang $X, N i$, Di X, Ma B, Niu S, et al. COVID19: melatonin as a potential adjuvant treatment. Life Sci. 2020;250:117583. https://doi.org/10.1016/j.Ifs.2020.117583

21. Shneider A, Kudriavtsev A, Vakhrusheva A. Can melatonin reduce the severity of COVID-19 pandemic? Int Rev Immunol. 2020:39(4):15362. https://doi.org/10.1080/08830185.2020.1756284
22. Giménez VMM, Inserra F, Tajer CD, Mariani J, Ferder L, Reiter RJ, et al. Lungs as target of COVID-19 infection: protective common molecular mechanisms of vitamin D and melatonin as a new potential synergistic treatment. Life Sci. 2020;254:117808. https://doi.org/10.1016/j.Ifs.2020.117808

23. Fan Y, Zhao K, Shi ZL, Zhou P. Bat coronaviruses in China. Viruses. 2019;11(3):210. https://doi.org/10.3390/v11030210

24. McMullan CJ, Schernhammer ES, Forman JP. Melatonin level and risk for type 2 diabetes: in reply. JAMA. 2013;310(5):537. https://doi.org/10.1001/jama.2013.7655

25. Abbott SM, Zee PC. Melatonin level and risk for type 2 diabetes. JAMA. 2013;310(5):536-7. https://doi.org/10.1001/ jama.2013.7649

26. Garaulet M, Gómez-Abellán P, Rubio-Sastre P, Madrid JA, Saxena R, Scheer FA. Common type 2 diabetes risk variant in MTNR1B worsens the deleterious effect of melatonin on glucose tolerance in humans. Metabolism. 2015;64(12):1650-7. https://doi.org/10.1016/j.metabol.2015.08.003

27. Herrera EA, González-Candia A. Comment on melatonin as a potential adjuvant treatment for COVID-19. Life Sci. 2020;253:117739. https://doi.org/10.1016/j. Ifs.2020.117739

28. By the 2019 American Geriatrics Society Beers Criteria ${ }^{\circledR}$ Update Expert Panel. American Geriatrics Society 2019 Updated AGS Beers Criteria ${ }^{\circledR}$ for potentially inappropriate medication use in older adults. J Am Geriatr Soc. 2019;67(4):674-94. https:// doi.org/10.1111/jgs.15767 